ARTICLE

\title{
Direct transfer of tri- and di-fluoroethanol units enabled by radical activation of organosilicon reagents
}

Xiang Chen ${ }^{1,2}$, Xingxing Gong ${ }^{1,2}$, Zhengyu $\mathrm{Li}^{1}$, Gang Zhou ${ }^{1}$, Zhihong Zhu', Weilu Zhang ${ }^{1}$, Shanshan Liu (1) ${ }^{1}$ \& Xiao Shen (iD) 1 四

Trifluoroethanol and difluoroethanol units are important motifs in bioactive molecules, but the methods to direct incorporate these units are limited. Herein, we report two organosilicon reagents for the transfer of trifluoroethanol and difluoroethanol units into molecules. Through intramolecular C-Si bond activation by alkoxyl radicals, these reagents were applied in allylation, alkylation and alkenylation reactions, enabling efficient synthesis of various tri(di) fluoromethyl group substituted alcohols. The broad applicability and general utility of the approach are highlighted by late-stage introduction of these fluoroalkyl groups to complex molecules, and the synthesis of antitumor agent $Z$ and its difluoromethyl analog $Z^{\prime}$.

\footnotetext{
${ }^{1}$ The Institute for Advanced Studies, Engineering Research Center of Organosilicon Compounds \& Materials, Ministry of Education, Wuhan University, 430072 Wuhan, China. ${ }^{2}$ These authors contributed equally: Xiang Chen, Xingxing Gong. ${ }^{凶}$ email: xiaoshen@whu.edu.cn
} 
F luorine incorporation has been a routine strategy for the design of new drugs and materials, because it can often improve the chemical, physical, and/or biological properties of organic molecules ${ }^{1,2}$. Fluoroalkylsilicon reagents, such as $\mathrm{TMSCF}_{3}$ (Rupert-Prakash reagent), $\mathrm{TMSCF}_{2} \mathrm{H}$, and others are widely used reagents in the synthesis of organofluorine compounds ${ }^{3}$. Among various fluorine-containing molecules, the secondary fluoroalkyl alcohols are of particular importance; monoamine oxidase A inhibitor Befloxatone ${ }^{4}$ and antitumor agent $\mathbf{Z}^{5}$ are examples of bioactive molecules containing trifluoroethanol motif (Fig. 1a). Anionic activation of C-Si bond of fluoroalkylsilicon reagents by Lewis bases is a powerful method to transfer a-fluoro carbanions into aldehydes, affording fluoroalkyl alcohol products (Fig. 1b) ${ }^{6-8}$. However, we enviosioned that the development of organosilicon reagents such as $\mathbf{1 a}$ and $\mathbf{2 a}$ which allows direct transfer of trifluoroethanol and difluoroethanol into organic molecules would represent a conceptually different means to construct fluoroalkyl alcohols (Fig. 1c). Actually, the synthetic chemistry based on carbonyl group (Fig. 1b) possesses some limitations: (1) many aldehydes are not stable and/or need multistep synthesis ${ }^{9,10} ;(2)$ it is hard to control the regioselectivity when there are more than one aldehyde sites in the same molecule. Moreover, the design and synthesis of pharmacuticals call for strategies to incorporate important structural motifs at latestage, because this will aviod de novo synthesis ${ }^{11,12}$.

Herein, we report two fluoroalkylsilicon reagents $\mathbf{1 a}$ and $\mathbf{2 a}$. Through intramolecular $\mathrm{C}-\mathrm{Si}$ bond activation by alkoxyl radicals $^{13-19}$, these developed $\beta$-fluorinated organosilicon reagents were successfully applied in radical allylation, alkylation, and alkenylation reactions, enabling efficient synthesis of a variety of fluoroalkyl group substituted alcohols (Fig. 1c). The broad applicability and general utility of the approach are highlighted by late-stage introduction of fluoroalkyl groups to complex molecules, such as the derivatives from biologically active naturally occuring epiandrosterone, cholesterol, testosterone, diosgenin, vitamin E, estrone, and ( $8 \alpha$ )-estradiol, and the synthesis of antitumor agent $\mathbf{Z}$ and its difluoromethyl analog $\mathbf{Z}^{\prime}$. Moreover, our radical reactions show conjunctive group tolerance to that of the traditional nucleophilic fluoroalkylation reactions with $\alpha$-fluoro carbanions ${ }^{3,20,21}$ (Radical reactions often show different reactivity to the anionic reactions, see refs. ${ }^{20,21}$ ).

\section{Results}

Preparation of reagents $1 \mathrm{a}$ and $2 \mathrm{a}$. The fluoroalkyl group transfer reagents $\mathbf{1 a}$ and $\mathbf{2 a}$ were easily synthesized in three steps (Fig. 2). Following the reported procedure 22 , with commercially available inexpensive trifluoroethanol $\mathbf{3}$ as starting material, we prepared difluorinated enol silyl ether 4 in $84 \%$ yield.
Electrophilic fluorination of compound 4 with Selectfluor afforded trifluoroacetylsilane $\mathbf{5}$ in $82 \%$ yield. Reagent $\mathbf{1 a}$ was then synthesized in $86 \%$ yield through reduction of acylsilane $\mathbf{5}$ with $\mathrm{NaBH}_{4}$. We also prepared different silyl group-substituted compounds 1b-1d through similar procedures as 1a in good yield (for details, see Supplementary Figs. 2-4). It is worthy to note that trifluoroacetyltriphenylsilane (precursor to 1d) can be synthesized directly from the reaction of $\mathrm{Ph}_{3} \mathrm{SiLi}$ and $\left(\mathrm{CF}_{3} \mathrm{CO}\right)_{2} \mathrm{O}$ in one step $^{23}$. The difluoroacetylsilane 6 was easily prepared in $79 \%$ yield through the hydrolysis of enol silyl ether $\mathbf{4}$ under acidic conditions. Reduction of compound $\mathbf{6}$ delivered difluoromethyl containing reagent $\mathbf{2 a}$ in $88 \%$ yield.

Attempts for anionic activation and design of radical activation. With reagent $\mathbf{1 a}$ in hand, we investigated the substitution reaction with allylic sulfone $7 \mathbf{a}$ as model substrate. Firstly, we tried anionic activation strategy which has been widely used in the $\mathrm{C}-\mathrm{Si}$ bond cleavage for the fluoroalkyl transfer reactions ${ }^{6-8}$. Common activators such as TBAF, CsF, KF, $t$-BuOK were tried, but no substitution product $8 \mathbf{a}$ or $9 \mathbf{a}$ was observed, albeit full conversion of compound 1a was observed (Fig. 3a). The decomposition of compound 1a could be explained by the facile fluoride elimination of $\beta$-fluoro carbanions (Fig. 3b) ${ }^{23-25}$. For example, $\mathrm{Xu}$ and coworkers reported the reaction of trifluoroacetyltriphenylsilane with Grignard reagents, but no desired trifluoromethylated alcohols were obtained. Instead, 2,2-difluoro enol silyl ethers were formed through nucleophilic addition, anion Brook rearrangment, and fluoride elimination processes ${ }^{23}$. It is known that fluorine radical possesses much higher energy than fluorine anion does (Fluorine possesses high electron affinity (3.448 eV), extreme ionization energy $(17.418 \mathrm{eV})$, see ref $1 \mathrm{a}, \mathrm{pp}$ $5-8)$. Therefore, we envisioned that in-situ generated carbon radical from alkoxyl radicals should not prefer $\beta-F$ elimination. Consequently, they could be trapped by radical acceptors to generate trifluoroethanol transfer products (Fig. 3b).

Identification of conditions for radical C-Si activation. With this idea in mind, we investigated a variety of conditions which could generate alkoxyl radicals (for details, see Supplementary Tables 1-3). After extensive screening, we found that employing 2 equivalent of $\mathrm{Mn}(\mathrm{OAc})_{3} \cdot 2 \mathrm{H}_{2} \mathrm{O}$ as oxidant, $\mathrm{DCM}$ as solvent led to allylation product in $68 \%$ yield (Table 1, entry 1). Further investigation revealed that with $20 \mathrm{~mol} \%$ of $\mathrm{Mn}(\mathrm{OAc})_{3} \cdot 2 \mathrm{H}_{2} \mathrm{O}$ as catalyst and 2.5 equivalent of TBPB as oxidant, product 8 was given in $61 \%$ yield (Table 1 , entry 2 ). Changing the silyl group from $\mathrm{SiMe}_{2} \mathrm{Ph}$ to $\mathrm{SiMePh}_{2}$ or $\mathrm{SiEt}_{3}$ resulted in only slightly decreased yield, but the $\mathrm{SiPh}_{3}$-substituted reagent 1d afforded much lower yield (Table 1, entries 3-5). It was found that Mn

c

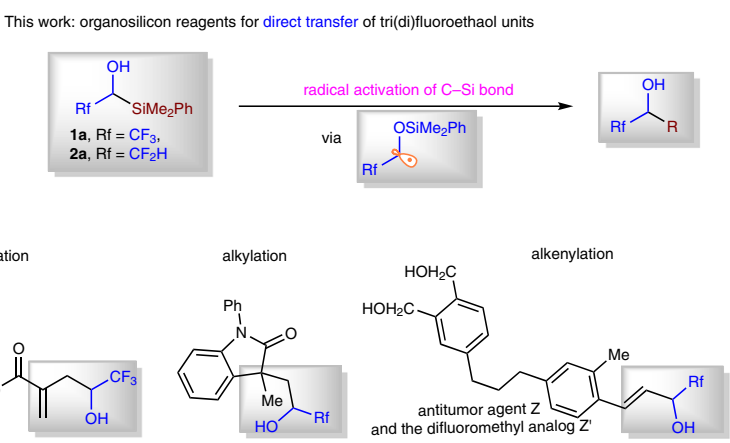

Fig. 1 Secondary fluoroalkyl alcohol synthesis with fluorinated organosilicon reagents. a Representative bioactive molecules containing trifluoroethanol unit. b Organosilicon reagents has been used in the synthesis for secondary fluoroalkyl alcohols via $\alpha$-fluoro carbanions transfer. c Organosilicon reagents for direct transfer of tri(di)fluoroethanol units via radical activation strategy is developed (this work). 


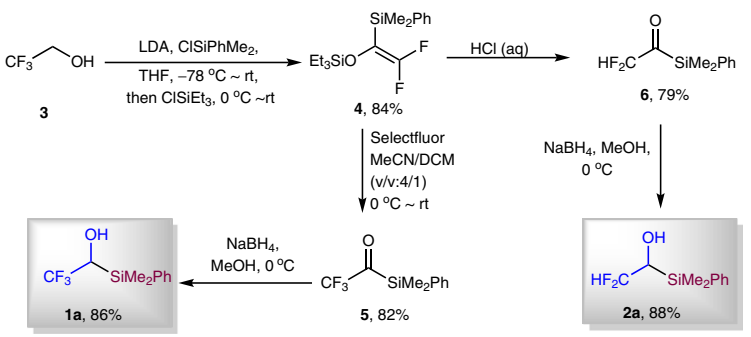

Fig. 2 Preparation of fluoroalkyl group transfer reagents $\mathbf{1 a}$ and $\mathbf{2 a}$. With commercially available $\mathbf{3}$, reagents $\mathbf{1 a}$ and $\mathbf{2} \mathbf{a}$ are easily prepared in three steps.

a

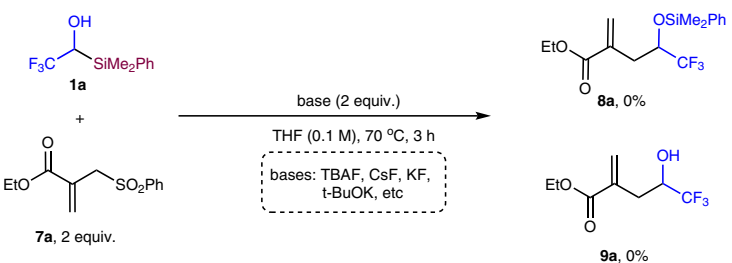

b

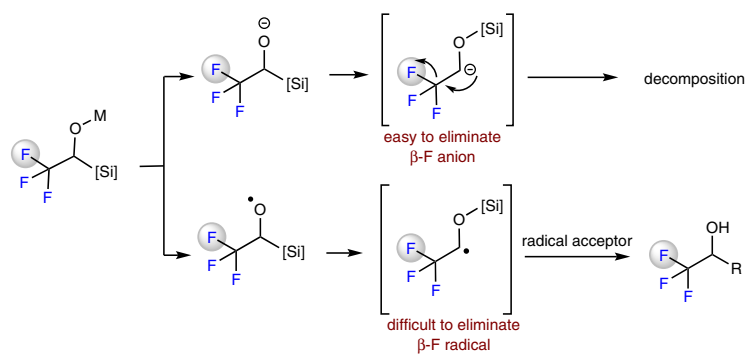

Fig. 3 Attempts for anionic activation and design of radical activation. a Attempts of anionic activation for trifluoroethanol transfer failed. b Facile $\beta-\mathrm{F}$ anion elimination might be the reason of the failure of anionic activation strategy; we designed a radical activation strategy based on the proposal that it is difficult to eliminate high-energy fluorine radical.

$(\mathrm{OAc})_{2} \cdot 4 \mathrm{H}_{2} \mathrm{O}$ can also be used as catalyst (Table 1, entry 6). When $20 \mathrm{~mol} \%$ of $\mathrm{Mn}(\mathrm{OAc})_{2} \cdot 4 \mathrm{H}_{2} \mathrm{O}$ was used, $1 \mathbf{a} / 7 \mathbf{a} / \mathrm{TBPB}$ is $1 / 2 /$ 2.5 , a yield of $81 \%$ can be detected by ${ }^{19} \mathrm{~F}$ NMR with $\mathrm{PhCF}_{3}$ as an internal standard (Table 1, entry 7). Control experiments verified that both $\mathrm{Mn}$ (II) catalyst and oxidant are necessary for the success of the reaction (Table 1, entries 8 and 9). When 2,2,2-trifluoroethanol was used instead of compound 1a in our reaction, no conversion of trifluoroethanol was observed (Table 1, entry 10). The high BDE of C-H bond $(409 \mathrm{~kJ} / \mathrm{mol})$ in trifluoroethanol might be one of the reasons for the difficulty in the generation of desired radical directly from trifluoroethanol under mild conditions $^{26-29}$ (There are limited reports on the generation of carbon radicals from trifluoroethanol under harsh conditions, see refs. ${ }^{27-29}$ ). The attempt to use Smith's condition ${ }^{19}$ to achieve the reaction between $1 \mathbf{a}$ and $7 \mathbf{a}$ failed to afford any amount of product 8a or 9a, highlighting the influence of $\mathrm{CF}_{3}$ group on the reactivity of reagent $\mathbf{1 a}$.

Synthesis of a-trifluoromethylated homoallylic alcohols. We next explored the scope of the allylic substitution reaction (Fig. 4). Both $\mathrm{Mn}(\mathrm{OAc})_{3} \cdot 2 \mathrm{H}_{2} \mathrm{O}$ and $\mathrm{Mn}(\mathrm{OAc})_{2} \cdot 4 \mathrm{H}_{2} \mathrm{O}$ are efficient catalysts for the transformation. When TBAF was used to quench the reaction, the silyl ether was converted to alcohol in one pot, and compound 9a was isolated in $62 \%$ yield. It was found that a variety of allylic sulfones ${ }^{30-34}$ bearing different groups could be

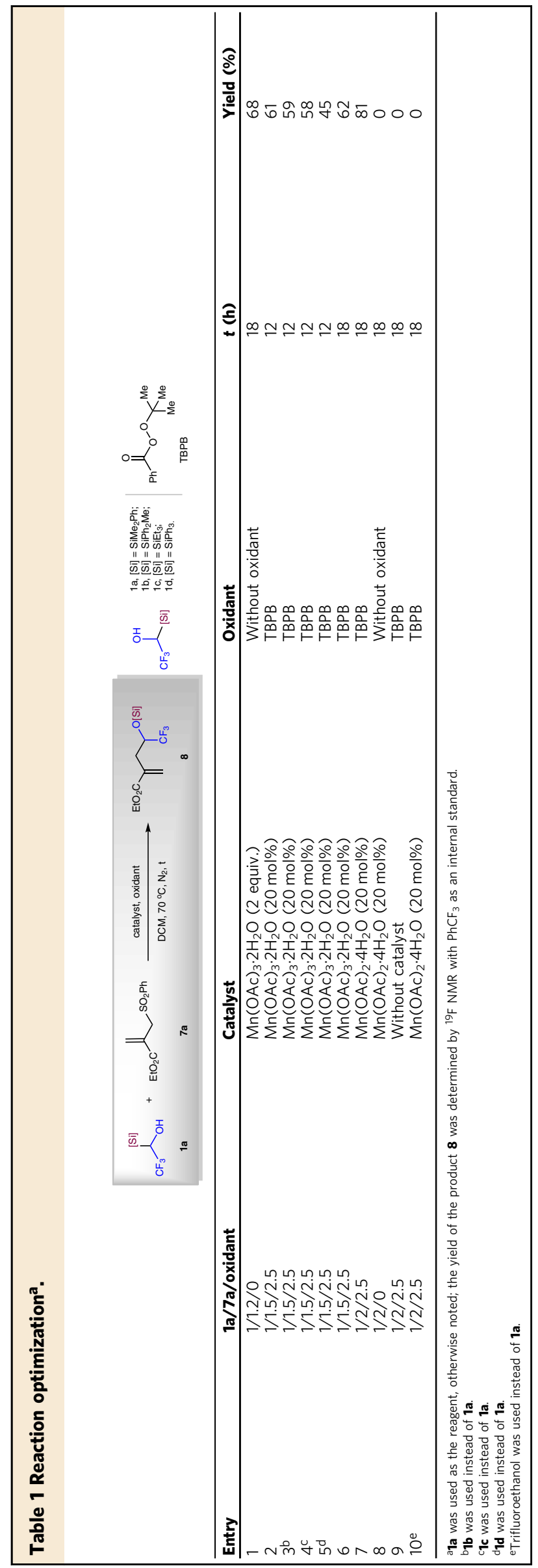




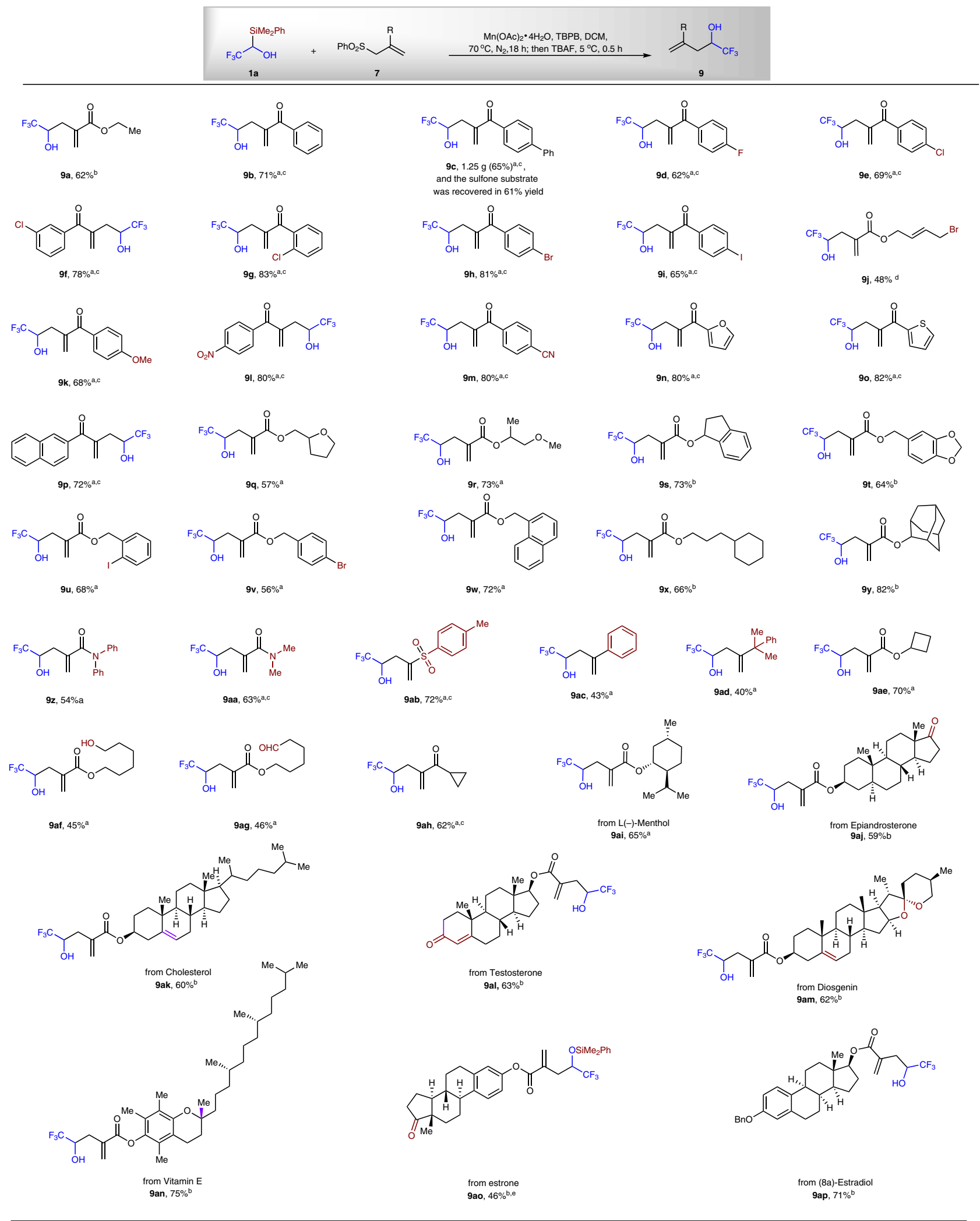

Fig. 4 Scope for the allylation of reagent $1 a \cdot{ }^{a} 1 a / 7=1 / 3, b 1 a / 7=1 / 2$, and ${ }^{c} \mathrm{Mn}(\mathrm{OAc})_{3} \cdot 2 \mathrm{H}_{2} \mathrm{O}$ was used instead of $\mathrm{Mn}(\mathrm{OAc})_{2} \cdot 4 \mathrm{H}_{2} \mathrm{O}$. ${ }^{\mathrm{d}} 2$ equivalent of $\mathrm{Mn}$ $(\mathrm{OAc})_{3} \cdot 2 \mathrm{H}_{2} \mathrm{O}$ was used without TBPB. eInstead of TBAF, water was used to quench the reaction.

used as the radical acceptors, affording the $a-\mathrm{CF}_{3}$-substituted homoallylic alcohols $9 \mathbf{9}-\mathbf{9 a p}$ in $40-83 \%$ yields. This reaction can be scaled up, and a yield of $65 \%$ was obtained for compound $9 \mathrm{c}$ ( $1.25 \mathrm{~g}$ isolated), and the sulfone $7 \mathrm{c}$ was recovered in $61 \%$ yield after silica gel chromatography. It is worth noting that the current allylation protocol can tolerate many functional groups. The $\mathrm{Csp}^{2}-\mathrm{F}, \mathrm{Csp}^{2}-\mathrm{Cl}, \mathrm{Csp}^{2}-\mathrm{Br}, \mathrm{Csp}^{2}-\mathrm{I}$ bond can be kept after the reaction, affording compounds $9 \mathbf{d}-\mathbf{9 i}, \mathbf{9 u}$, and $\mathbf{9 v}$ in $56-83 \%$ 
yields. Moreover, allylic bromide can also be tolerated (9j, $48 \%$ yield). These functional groups are well-known convertible motifs under transition metal-mediated/catalyzed reactions. Electron donating OMe group, electron withdrawing groups, such as $\mathrm{NO}_{2}$, $\mathrm{CN}$ can also be tolerated, affording compounds $9 \mathbf{k}-9 \mathbf{m}$ in $68-80 \%$ yields. Electron-rich heterocyclic groups, such as furyl and thienyl are also be tolerated (9n, $80 \%$ yield; 90 , $82 \%$ yield). Naphthyl-substituted product was also successfully made via the Mn-catalyzed substitution reaction, affording alcohol $9 p$ in $72 \%$ yield. A variety of alkyl ethers and benzylic alcohol-derived esters are tolerated under the current oxidation conditions, and alcohols 9q-9w were obtained in $56-73 \%$ yields. Not only estersubstituted and ketone-substituted allylic sulfones, but also amide, sulfone, phenyl, and alkyl groups-substituted allylic sulfones can be applied in the current substitution process, affording corresponding $\mathrm{a}-\mathrm{CF}_{3}$-substituted homoallylic alcohols $(\mathbf{9 z}-\mathbf{9 a d}$, $40-72 \%$ yields). Moreover, this substitution process is compatible with many base-sensitive functionality, such as primary alcohol (9af, $45 \%$ yield), alkyl aldehyde (9ag, $46 \%$ yield), alkyl ketone (9ah, $62 \%$ yield; 9 aj, $59 \%$ yield; 9 al, $63 \%$ yield; 9 ao, $46 \%$ yield). It is worthy to note that the above-mentioned aldehyde and ketonecontaining products are challenging to be synthesized by methods based on these functional groups ${ }^{3}$. In addition, the current radical allylic substitution can be applied in the functionalization of complex molecules, such as the derivatives from biologically active naturally occuring epiandrosterone, cholesterol, testosterone, diosgenin, vitamin $\mathrm{E}$, estrone, and (8a)-estradiol, affording corresponding alcohols 9ai-9ap in $46-75 \%$ yields.

Synthesis of $\alpha$-trifluoromethylated alkyl alcohols. After achieving the radical $\mathrm{C}-\mathrm{Si}$ bond activation to access $\alpha$ trifluoromethylated homoallylic alcohols, we wondered whether the same strategy can be applied in double functionalization of alkenes to prepare $\alpha$-trifluoromethylated alkyl alcohols. Acryl amides 10 were chosen to test the possibility $35-38$. To our delight, under $\mathrm{Mn}(\mathrm{II}) / \mathrm{TBPB}$ conditions, various acryl amides can be converted to corresponding trifluoromethylated alcohols $\mathbf{1 1}$ in $63-91 \%$ yield (Fig. 5). Me, Ph, and Bn groups on the $\mathrm{N}$ of amides do not affect the reaction. The reaction tolerates halides, such as $\mathrm{F}$ and $\mathrm{Cl}$. Both electron-donating $\mathrm{OMe}$ and electron-withdrawing $\mathrm{CO}_{2} \mathrm{Me}$ on the arenes were maintained after the reaction. It is worthy to note that compounds $\mathbf{1 1}$ are difficult to be synthesized through the nucleophilic trifluoromethylation reaction of aldehydes with $\mathrm{TMSCF}_{3}$, because the aldehydes themselves need multistep synthesis ${ }^{10}$.

Synthesis of a-trifluoromethylated allylic alcohols. Allylic alcohols are important synthetic intermediates for a variety of transformations. Moreover, fluorinated compounds possess unique chemical, physical, and biological properties. Therefore, the development of one step synthesis of $\alpha$-trifluoromethylated allylic alcohols from readily available starting materials are highly desired. Previous methods to prepare $\alpha$-trifluoromethylated allylic alcohols mainly rely on nucleophilic trifluoromethylation of $\alpha, \beta-$ unsaturated aldehydes ${ }^{39-43}$. $\alpha, \beta$-Unsaturated carboxylic acids are easy to be synthesized and many of them are commercially available. Moreover, they are more stable under atmosphere than corresponding $\alpha, \beta$-unsaturated aldehydes. They have been used in the decarboxylative trifluoromethylation reactions for the synthesis of $\mathrm{CF}_{3}$-substituted alkenes ${ }^{44,45}$. Encouraged by the success of synthesizing homoallylic and alkyl alcohols with 1a as reagent under the radical $\mathrm{C}-\mathrm{Si}$ bond activation conditions, we studied the reaction between 1a and acids $\mathbf{1 2}$ to prepare $\alpha$ trifluoromethylated allylic alcohols (Fig. 6). The reaction conditions are slightly different from the above allylation and alkylation reactions: (1) both hexane and DCM could be used as solvent; (2) the desilylation step was performed under lower temperature $\left(-10\right.$ vs. $\left.5^{\circ} \mathrm{C}\right)$ to avoid side reactions. It can be found from Fig. 7 that various $\alpha, \beta$-unsaturated carboxylic acids containing $\mathrm{F}, \mathrm{Cl}, \mathrm{Br}$, $\mathrm{MeO}, \mathrm{BnO}$, and $\mathrm{CF}_{3}$ substituents were successfully converted to corresponding $\alpha$-trifluoromethylated allylic alcohols in 51-75\% yield. To the best of our knowledge, there has been no report on the synthesis of $\alpha$-trifluoromethylated allylic alcohols with unsaturated carboxylic acids before this work.

Radical C-Si activation for difluoroethanol unit transfer. Difluoromethyl group $\left(\mathrm{CF}_{2} \mathrm{H}\right)$ is isopolar and isosteric to an $\mathrm{SH}$

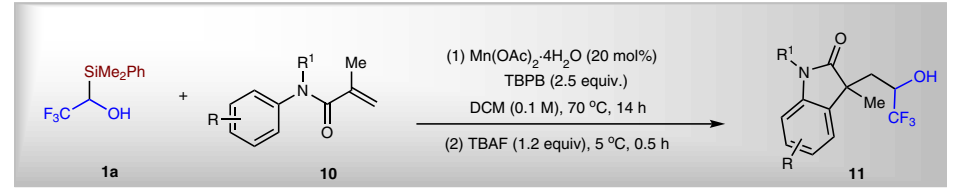

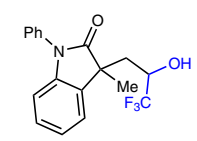

$11 a, 91 \%$

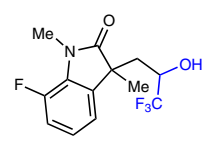

$11 d, 80 \%$

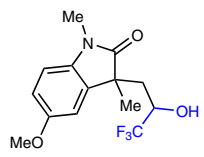

$11 \mathrm{~g}, 71 \%$

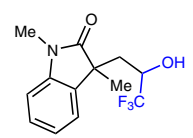

11b, $76 \%$

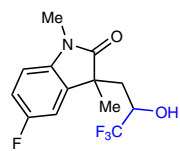

11 e, $84 \%$

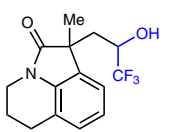

11h, $77 \%$

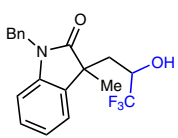

$11 \mathrm{c}, 79 \%$

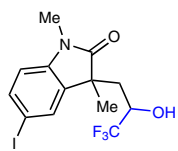

11f, $72 \%$

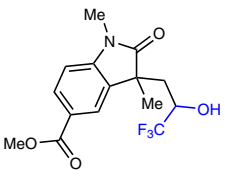

$11 i, 63 \%$

Fig. 5 Synthesis of $\boldsymbol{\alpha}$-trifluoromethylated alkyl alcohols. All reactions were run under the standard conditions with $\mathbf{1 a / 1 0}=1 / 2$. 

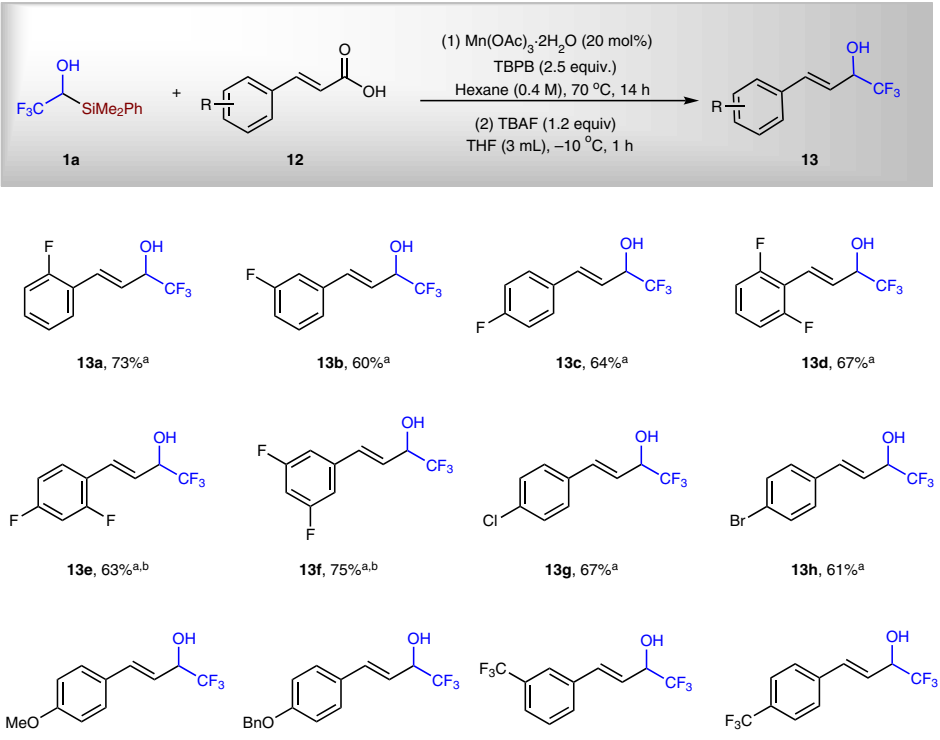

$\begin{array}{llll}13 \mathrm{i}, 54 \%^{\mathrm{a}} & 13 \mathrm{j}, 51 \%^{\mathrm{a}} & 13 \mathrm{k}, 65 \%^{\mathrm{a}} & 131,72 \% \mathrm{a}\end{array}$

Fig. 6 Synthesis of $\boldsymbol{\alpha}$-trifluoromethylated allylic alcohols. aReactions were run under standard conditions with $\mathbf{1 a} / \mathbf{1 2}=1 / 2$. bDCM was used as solvent instead of hexanes.

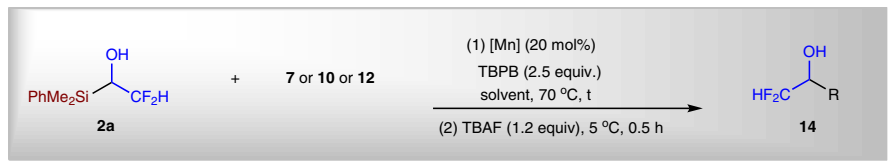

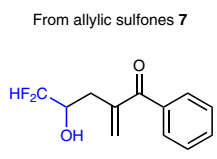

$14 a, 80 \%$ a, c, f<smiles>C=C(CC(C)C)C(=O)c1ccc(F)cc1</smiles>

$14 \mathrm{~b}, 66^{\mathrm{a}, \mathrm{c}, \mathrm{f}}$<smiles>C=C(CC(C)O)C(=O)N(P)P</smiles>

$14 \mathrm{c}, 72 \% \mathrm{~b}, \mathrm{c}, \mathrm{e}$
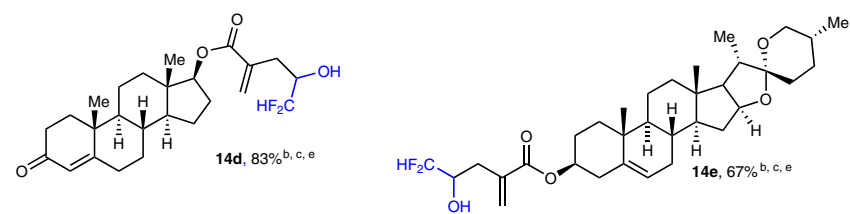

From acryl amides 10

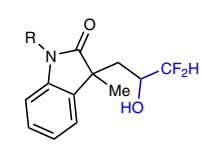

14f, $\mathrm{R}=\mathrm{Ph}, 81 \% \mathrm{a}, \mathrm{c}, \mathrm{f}$ $14 \mathrm{~g}, \mathrm{R}=\mathrm{Bn}, 78 \% \mathrm{a}, \mathrm{c}, \mathrm{t}$

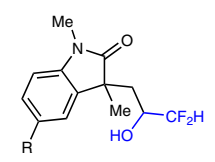

14h, $\mathrm{R}=\mathrm{CO}_{2} \mathrm{Me}, 76 \% \mathrm{a}, \mathrm{c}, \mathrm{t}$ $14 i, \mathrm{R}=\mathrm{OMe}, 82 \% \mathrm{a}, \mathrm{c}, \mathrm{f}$
From a b-unsaturated acids 12<smiles>OC(C=Cc1ccccc1)C(F)F</smiles>

$14 \mathrm{j}, \mathrm{R}=2,6-\mathrm{F}, 60 \%$ a, $\mathrm{d}$,

$14 \mathbf{k}, \mathrm{R}=4-\mathrm{F}, 58 \%$ a, $\mathrm{d}, \mathrm{f}$

14l, $R=4-\mathrm{OMe}, 54 \%$ a, d,

Fig. 7 Synthesis of $\boldsymbol{\alpha}$-difluoromethylated alcohols. ${ }^{\mathrm{a} n n}(\mathrm{OAc})_{3} \cdot 2 \mathrm{H}_{2} \mathrm{O}(20 \mathrm{~mol} \%)$ was used as catalyst. b ${ }^{\mathrm{Mn}}(\mathrm{OAc})_{2} \cdot 4 \mathrm{H}_{2} \mathrm{O}(20 \mathrm{~mol} \%)$ was used as catalyst. ${ }^{C} D C M(0.1 \mathrm{M})$ was used as solvent. ${ }^{\mathrm{d}}$ Hexane $(0.4 \mathrm{M})$ was used as solvent. ${ }^{\mathrm{e}} t=18 \mathrm{~h}$ and ${ }^{\mathrm{f}} t=14 \mathrm{~h}$.

or $\mathrm{OH}$ group, and can also behave as a hydrogen donor through hydrogen bonding 46,47 . Therefore, difluoromethylated compounds are strong candidate for drugs. There are examples showing that the $\mathrm{CF}_{2} \mathrm{H}$-containing compounds exhibit higher bioactivity than their $\mathrm{CF}_{3}$-containing counterparts ${ }^{48,49}$. Encouraged by the above success of radical $\mathrm{C}-\mathrm{Si}$ bond activation to access trifluoromethylated allylic, alkyl, and alkenyl alcohols, we extended the strategy to directly transfer 2,2-difluoroethanol to organic molecules with reagent $\mathbf{2 a}$ (Fig. 7). To the best of our knowledge, there has been no report of the synthetic application of carbon radical from 2,2-difuoroethanol. Under the similar reaction conditions as that of $\mathbf{1 a}$, with allylic sulfones as substrates, difluoromethylated homoallylic alcohols 14a-14c were prepared in $66-80 \%$ yield. Late-stage functionalization of two complex molecules are also successful; $14 \mathrm{~d}$ and $\mathbf{1 4 e}$ were isolated in $83 \%$ and $67 \%$ yield, respectively. The reactions of acryl amides performed well, affording $\mathbf{1 4 f}-\mathbf{1 4} \mathbf{i}$ in $76-82 \%$ yield. $\mathrm{Ph}, \mathrm{Bn}$, and Me groups on the $\mathrm{N}$ atom were tolerated; both electronwithdrawing $\mathrm{CO}_{2} \mathrm{Me}$ and electron-donating OMe groups on the aromatic ring were maintained after the reactions. Three 

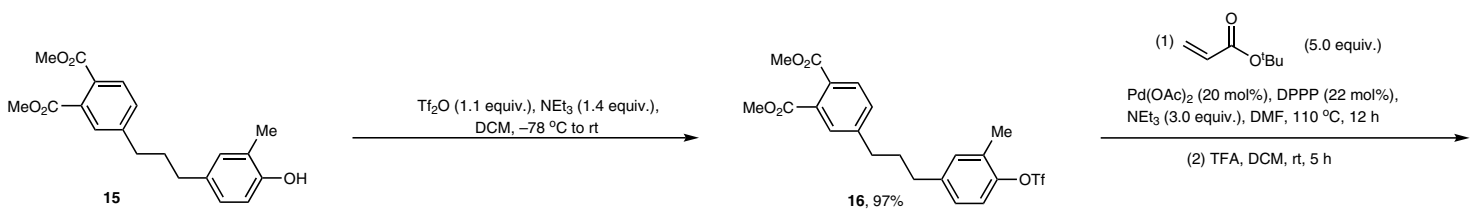

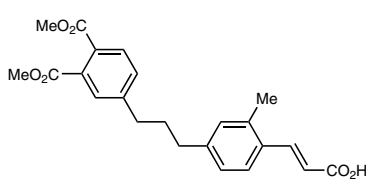

$17,76 \%$ for two steps

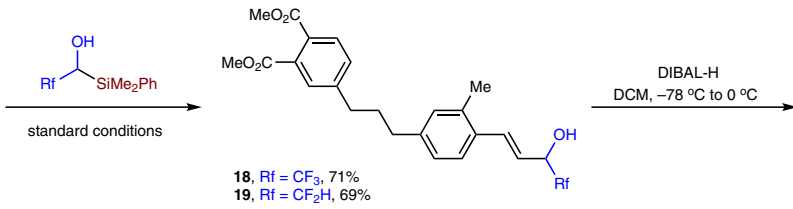

18, $\mathrm{Rf}=\mathrm{CF}_{3}, 71 \%$
19, $\mathrm{Rf}=\mathrm{CF}_{2} \mathrm{H}, 69 \%$

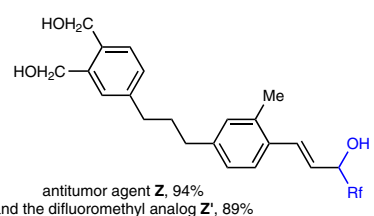

Fig. 8 Synthesis of antitumor agent $\mathbf{Z}$ and its difluoromethyl analog $\mathbf{Z}^{\prime} \cdot \mathrm{Tf}_{2} \mathrm{O}$ trifluoromethanesulfonic anhydride, DPPP bis(diphenylphosphino)propane, TFA trifluoroacetic acid, DIBAL-H diisobutylaluminum hydride.

a

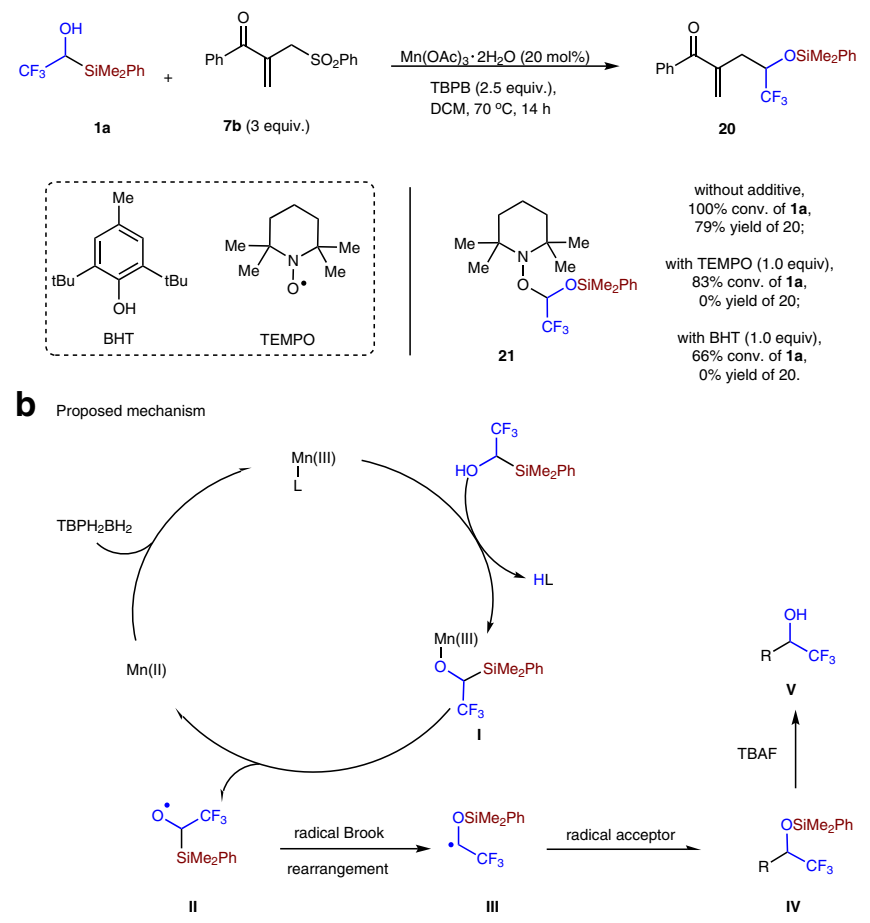

Fig. 9 Radical inhibition experiments and proposed mechanism. a TEMPO and $\mathrm{BHT}$ efficiently inhibited the allylation reaction, supporting radical process might be involved. $\mathbf{b}$ A plausible mechanism is proposed.

examples of $\alpha, \beta$-unsaturated carboxylic acids demonstrated the utility of synthesis of difluoromethyl group-substituted allylic alcohols $\mathbf{1 4 j - 1 4 l}$ in synthetically useful yield.

Synthesis of antitumor agent $\mathrm{Z}$ and its difluoromethyl analog $Z^{\prime}$. After achieving the direct transfer of 2,2,2-trifluoroethanol and 2,2 -difluoroethanol to simple $\alpha, \beta$-unsaturated carboxylic acids, we tested whether our methodology can be applied in the synthesis of antitumor agent $\mathbf{Z}$ (Fig. 8) $)^{5}$. Starting from known compound $15^{5}$, the protection of phenol afforded compound $\mathbf{1 6}$ in $97 \%$ yield. $\alpha, \beta$-Unsaturated carboxylic acid $\mathbf{1 7}$ was then synthesized in $76 \%$ yield after Heck reaction and selective hydrolysis of the ester. The radical reactions performed well under our standard conditions, affording compounds 18 and 19 in $71 \%$ yield and $69 \%$ yield, respectively. Hydrolysis of the esters afforded the final product $\mathbf{Z}$ and $\mathbf{Z}^{\prime}$ in $94 \%$ and $89 \%$ yield, respectively.
Mechanism of the study. The radical inhibition experiments revealed that addition of 1 equiv. of TEMPO or BHT can completely inhibit the allylation reaction, albeit more than $60 \%$ of compound 3a were consumed in both cases (Fig. 9a). In addition, compound 21 was detected by HRMS when TEMPO was added into the reaction (for details, see Supporting Information). Therefore, radical process might be involved in current substitution reaction. Our investigation revealed that $\mathrm{Mn}$ $(\mathrm{OAc})_{3} \cdot 2 \mathrm{H}_{2} \mathrm{O}$ is able to mediate the reaction without external oxidant, but $\mathrm{Mn}(\mathrm{OAc})_{2} \cdot 4 \mathrm{H}_{2} \mathrm{O}$ cannot mediate the reaction without TBPB (Table 1, entries 1 and 8). Based on these results, we propose a possible mechanism as shown in Fig. 9b. Ligand exchange between $\mathrm{Mn}$ (III) species and alcohol 1a might generate intermediate I, which undergoes homolysis to produce alkoxyl radical II and $\mathrm{Mn}$ (II) intermediate ${ }^{50-53}$. Carbon radical III would be generated through Brook rearrangement, and then undergo further reaction to generate product IV. Mn(III) catalyst is likely to be regenerated by the oxidation of $\mathrm{Mn}$ (II) by TBPB. The alcohol product $\mathbf{V}$ would be generated after the desilylation step. It is worthy to note that the reaction pathways in the allylation, alkylation, and alkenylation reactions are probably different (for the proposed possibilities, see Supplementary Figs. 13-15). As for the nature of radical III, we propose that they are nucleophilic radicals. The following facts support this proposal: (1) the reaction partners in the above three kinds of reactions are electrondeficient olefins; (2) more electron-deficient substrate afforded higher yield (for example, Fig. 5, 9ac, $43 \%$ yield; 9ae, $70 \%$ yield); (3) the carbon radical generated from trifluoroethanol under $\gamma$ ray irradiation could add to highly electrophilic hexafluoro-2butyne ${ }^{27}$.

\section{Discussion}

In conclusion, we have developed two fluorinated organosilicon reagents, which were used in direct transfer of trifluoroethanol and difluoroethanol units into organic molecules. A radical C-Si bond activation strategy was developed to solve the problem of $\beta$ fluorine elimination in anionic activation methods. Upon intramolecular activation of $\mathrm{C}-\mathrm{Si}$ bond by alkoxyl radicals, the $\beta$ fluoro carbon radicals were generated and participated in efficient allylation, alkylation, and alkenylation reactions, enabling efficient synthesis of numerous fluoroalkyl alcohols. The broad applicability and general utility of the approach are highlighted by late-stage introduction of fluoroalkyl groups to complex molecules and the synthesis of antitumor agent $\mathbf{Z}$ and its difluoromethyl analog $\mathbf{Z}^{\prime}$. Further application of the radical C-Si bond activation of organosilicon reagents are underway in our lab.

\section{Methods}

Typical synthesis of compound 9. Under $\mathrm{N}_{2}$ atmosphere, to a dried $10 \mathrm{~mL}$ Schlenk tube equipped with a magnetic stir bar containing $\mathrm{Mn}(\mathrm{OAc})_{2} \cdot 4 \mathrm{H}_{2} \mathrm{O}$ 
(14.7 mg, $0.06 \mathrm{mmol}, 20 \mathrm{~mol} \%)$ was added DCM $(3 \mathrm{~mL}, 0.1 \mathrm{M}), \mathbf{1 a}(70.2 \mathrm{mg}$, $0.3 \mathrm{mmol}$ ), $7 \mathbf{a}(152.4 \mathrm{mg}, 0.6 \mathrm{mmol}, 2.0$ equiv.), and TBPB (145.7 mg, $0.75 \mathrm{mmol}$, 2.5 equiv.) sequentially. The tube was sealed, and the resulting mixture was kept stirring at $70^{\circ} \mathrm{C}$ in a heating block for $18 \mathrm{~h}$. The mixture was then cooled to $5^{\circ} \mathrm{C}$ with ice bath, TBAF (1.0 M in THF, $0.36 \mathrm{~mL}, 0.36 \mathrm{mmol}, 1.2$ equiv.) was added and the resulting mixture was stirred at $5^{\circ} \mathrm{C}$ for $0.5 \mathrm{~h}$. The reaction mixture was quenched with water $(2 \mathrm{~mL})$, extracted with DCM $(3 \times 10 \mathrm{~mL})$ and organic phase was combined and washed with brine, dried over $\mathrm{Na}_{2} \mathrm{SO}_{4}$, concentrated under reduced pressure. The crude product was purified with column chromatography on silica gel (200-300 mesh) and PE/EA (20/1-10/1, v/v) as eluent to afford $40.0 \mathrm{mg}$ of compound $9 \mathrm{a}$ as a colorless oil (62\% yield).

\section{Data availability}

The authors declare that all data supporting the findings of this study are available within the article and Supplementary Information files, and also are available from the corresponding author on reasonable request.

Received: 24 November 2019; Accepted: 30 April 2020; Published online: 02 June 2020

\section{References}

1. Kirsch, P. Modern Fluoroorganic Chemistry: Synthesis, Reactivity, Applications. (Wiley-VCH, Weinheim, 2013).

2. Purser, S., Moore, P. R., Swallow, S. \& Gouverneur, V. Fluorine in medicinal chemistry. Chem. Soc. Rev. 37, 320-330 (2008).

3. Liang, T., Neumann, C. N. \& Ritter, T. Introduction of fluorine and fluorinecontaining functional groups. Angew. Chem. Int. Ed. 52, 8214-8264 (2013).

4. Wouters, J. et al. A reversible monoamine oxidase an inhibitor, befloxatone: structural approach of its mechanism of action. Bioorg. Med. Chem. 7, 1683-1693 (1999).

5. Biadatti, T., Thoreau, E., Voegel, J. \& Jomard, A. Analogues of vitamin D. PCT Int. Appl. WO 2004020379 A1 20040311 (2004).

6. Prakash, G. K. S., Krishnamurti, R. \& Olah, G. A. Synthetic methods and reactions. 141. Fluoride-induced trifluoromethylation of carbonyl compounds with trifluoromethyltrimethylsilane (TMS-CF3). A trifluoromethide equivalent. J. Am. Chem. Soc. 111, 393-395 (1989).

7. Prakash, G. K. S. et al. Long-lived trifluoromethanide anion: a key intermediate in nucleophilic trifluoromethylations. Angew. Chem. Int. Ed. 53, 11575-11578 (2014)

8. Zhao, Y., Huang, W., Zheng, J. \& Hu, J. Efficient and direct nucleophilic difluoromethylation of carbonyl compounds and imines with me3sicf2h at ambient or low temperature. Org. Lett. 13, 5342-5345 (2011).

9. He, Y., Tian, M.-M., Zhang, X.-Y. \& Fan, X.-S. Synthesis of 4-Oxo-but-2-enals through tBuONO and TEMPO-promoted cascade reactions of homoallylic alcohols. Asian J. Org. Chem. 5, 1318-1322 (2016).

10. Ou, W., Zhang, G., Wu, J. \& Su, C. Photocatalytic cascade radical cyclization approach to bioactive indoline-alkaloids over donor-acceptor type conjugated microporous polymer. ACS Catal. 9, 5178-5183 (2019).

11. Cernak, T., Dykstra, K. D., Tyagarajan, S., Vachal, P. \& Krska, S. W. The medicinal chemist's toolbox for late stage functionalization of drug-like molecules. Chem. Soc. Rev. 45, 546-576 (2016).

12. Neumann, C. N. \& Ritter, T. Late-stage fluorination: fancy novelty or useful tool? Angew. Chem. Int. Ed. 54, 3216-3221 (2015).

13. Renaud, P. \& Sibi, M. P. (eds) Radicals in Organic Synthesis (Wiley-VCH, Weinheim, 2001).

14. Hu, A., Guo, J.-J., Pan, H. \& Zuo, Z. Selective functionalization of methane, ethane, and higher alkanes by cerium photocatalysis. Science 361, 668-672 (2018).

15. Jia, K., Zhang, F., Huang, H. \& Chen, Y. Visible-light-induced alkoxyl radical generation enables selective $\mathrm{C}(\mathrm{sp} 3)-\mathrm{C}(\mathrm{sp} 3)$ bond cleavage and functionalizations. J. Am. Chem. Soc. 138, 1514-1517 (2016).

16. Ren, R., Zhao, H., Huan, L. \& Zhu, C. Manganese-catalyzed oxidative azidation of cyclobutanols: regiospecific synthesis of alkyl azides by $\mathrm{C}-\mathrm{C}$ bond cleavage. Angew. Chem. Int. Ed. 54, 12692-12696 (2015).

17. Zhu, Y. et al. Silver-catalyzed remote Csp3-H functionalization of aliphatic alcohols. Nat. Commun. 9, 2625 (2018).

18. Paredes, M. D. \& Alonso, R. On the radical Brook rearrangement. Reactivity of $\alpha$-silyl alcohols, $\alpha$-silyl alcohol nitrite esters, and $\beta$-haloacylsilanes under radical-forming conditions. J. Org. Chem. 65, 2292-2304 (2000).

19. Deng, Y., Liu, Q. \& Smith, A. B. Oxidative $[1,2]$-Brook rearrangements exploiting single-electron transfer: photoredox-catalyzed alkylations and arylations. J. Am. Chem. Soc. 139, 9487-9490 (2017).

20. Wang, L., Lear, J. M., Rafferty, S. M., Fosu, S. C. \& Nagib, D. A. Ketyl radical reactivity via atom transfer catalysis. Science 362, 225-229 (2018).
21. Fu, G. C. Transition-metal catalysis of nucleophilic substitution reactions: a radical alternative to $\mathrm{SN} 1$ and SN2 processes. ACS Cent. Sci. 3, 692-700 (2017).

22. Higashiya, S. et al. Synthesis of mono- and difluoroacetyltrialkylsilanes and the corresponding enol silyl ethers. J. Org. Chem. 69, 6323-6328 (2004).

23. Jin, F., Jiang, B. \& Xu, Y. Trifluoroacetyltriphenylsilane as a potentially useful fluorine-containing building block. Preparation and its transformation into 2,2-difluoro enol silyl ethers. Tetrahedron Lett. 33, 1221-1224 (1992).

24. Uneyama, K., Katagiri, T. \& Amii, H. $\alpha$-Trifluoromethylated carbanion synthons. Acc. Chem. Res. 41, 817-829 (2008).

25. Decostanzi, M. et al. Brook/elimination/aldol reaction sequence for the direct one-pot preparation of difluorinated aldols from (trifluoromethyl)trimethylsilane and acylsilanes. Adv. Synth. Catal. 358, 526-531 (2016)

26. Morozov, I. et al. Hydroxyl radical reactions with halogenated ethanols in aqueous solution: Kinetics and thermochemistry. Int. J. Chem. Kinet. 40, 174-188 (2008).

27. Chambers, R. D., Jones, C. G. P. \& Silverster, M. J. Free-radical chemistry. Part 7[1]. Additions to hexafluoro-2-butyne. J. Fluor. Chem. 32, 309-317 (1986).

28. Brown, S. H. \& Crabtree, R. H. Making mercury-photosensitized dehydrodimerization into an organic synthetic method: vapor pressure selectivity and the behavior of functionalized substrates. J. Am. Chem. Soc. 111, 2935-2946 (1989).

29. Kamitanaka, T. et al. H-Bonding-promoted radical addition of simple alcohols to unactivated alkenes. Green Chem. 19, 5230-5235 (2017).

30. Knight, D. J., Lin, P. \& Whitham, G. H. 1,3-Rearrangements of some allylic sulphones. J. Chem. Soc. Perkin Trans. 1, 2707-2713 (1987).

31. Kim, S. \& Lim, C. J. Tin-free radical-mediated C-C bond formations with alkyl allyl sulfones as radical precursors. Angew. Chem. Int. Ed. 41, 3265-3267 (2002).

32. Qi, L. \& Chen, Y. Polarity-reversed allylations of aldehydes, ketones, and imines enabled by Hantzsch ester in photoredox catalysis. Angew. Chem. Int Ed. 55, 13312-13315 (2016)

33. Zhao, Q.-Q., Chen, J., Yan, D.-M., Chen, J.-R. \& Xiao, W.-J. Photocatalytic hydrazonyl radical-mediated radical cyclization/allylation cascade: synthesis of dihydropyrazoles and tetrahydropyridazines. Org. Lett. 19, 3620-3623 (2017).

34. Wu, K., Wang, L., Colón-Rodríguez, S., Flechsig, G.-U. \& Wang, T. Amidyl radical directed remote allylation of unactivated sp3 $\mathrm{C}-\mathrm{H}$ bonds by organic photoredox catalysis. Angew. Chem. Int. Ed. 58, 1774-1778 (2019).

35. Wei, W.-T. et al. Synthesis of oxindoles by iron-catalyzed oxidative 1,2alkylarylation of activated alkenes with an aryl $\mathrm{C}(\mathrm{sp} 2)-\mathrm{H}$ bond and a $\mathrm{C}$ (sp3)-H bond adjacent to a heteroatom. Angew. Chem. Int. Ed. 52, 3638-3641 (2013).

36. Li, Y.-M. et al. Direct annulations toward phosphorylated oxindoles: silvercatalyzed carbo-phosphorus functionalization of alkenes. Angew. Chem. Int. Ed. 52, 3972-3976 (2013).

37. $\mathrm{Mu}, \mathrm{X}$., Wu, T., Wang, H.-Y., Guo, Y.-L. \& Liu, G. Palladium-catalyzed oxidative aryltrifluoromethylation of activated alkenes at room temperature. $J$. Am. Chem. Soc. 134, 878-881 (2012).

38. Wu, L., Wang, F., Chen, P. \& Liu, G. Enantioselective construction of quaternary all-carbon centers via copper-catalyzed arylation of tertiary carbon-centered radicals. J. Am. Chem. Soc. 141, 1887-1892 (2019).

39. Trost, B. M. \& Debien, L. Palladium-catalyzed trimethylenemethane cycloaddition of olefins activated by the $\sigma$-electron-withdrawing trifluoromethyl group. J. Am. Chem. Soc. 137, 11606-11609 (2015).

40. Song, J. J. et al. N-heterocyclic carbene catalyzed trifluoromethylation of carbonyl compounds. Org. Lett. 7, 2193-2196 (2015).

41. Levin, V. V., Dilman, A. D., Belyakov, P. A., Struchkova, M. I. \& Tartakovsky, V. A. Nucleophilic trifluoromethylation with organoboron reagents. Tetrahedron Lett. 52, 281-284 (2011).

42. Aikawa, K., Toya, W., Nakamura, Y. \& Mikami, K. Development of (trifluoromethyl)zinc reagent as trifluoromethyl anion and difluorocarbene sources. Org. Lett. 17, 4996-4999 (2015).

43. Czerwinski, P., Molga, E., Cavallo, L., Poater, A. \& Michalak, M. NHC-copper (I) halide-catalyzed direct alkynylation of trifluoromethyl ketones on water. Chem.-Eur. J. 22, 8089-8094 (2016).

44. He, Z., Luo, T., Hu, M., Cao, Y. \& Hu, J. Copper-catalyzed di-and trifluoromethylation of $\alpha, \beta$-unsaturated carboxylic acids: a protocol for vinylic fluoroalkylations. Angew. Chem. Int. Ed. 51, 3944-3947 (2012).

45. Li, G. et al. Nickel-catalyzed decarboxylative difluoroalkylation of $\alpha, \beta-$ unsaturated carboxylic acids. Angew. Chem. Int. Ed. 55, 3491-3495 (2016).

46. Meanwell, N. A. Synopsis of some recent tactical application of bioisosteres in drug design. J. Med. Chem. 54, 2529-2591 (2011). 
47. Erickson, J. A. \& McLoughlin, J. I. Hydrogen bond donor properties of the difluoromethyl group. J. Org. Chem. 60, 1626-1631 (1995).

48. Gauthier, J. Y. et al. The identification of 4,7-disubstituted naphthoic acid derivatives as UDP-competitive antagonists of P2Y14. Bioorg. Med. Chem. Lett. 21, 2836 (2011). 283.

49. Graneto, M. J. \& Philips, W. J. 3-difluoromethylpyrazolecarbox-amide fungicides, compositions and use. U.S. Patent 5,093,347 (1992).

50. Demir, A. S. \& Emrullahoglu, M. Manganese(III) acetate: a versatile reagent in organic chemistry. Curr. Org. Synth. 4, 321-351 (2007).

51. Chiba, S. Mn(III)-catalyzed radical reactions of 1,3-dicarbonyl compounds and cyclopropanols with vinyl azides for divergent synthesis of azaheterocycles. Chimia 66, 377-381 (2012).

52. Crossley, S. W. M., Obradors, C., Martinez, R. M. \& Shenvi, R. A. Mn-, Fe-, and Co-catalyzed radical hydrofunctionalizations of olefins. Chem. Rev. 116, 8912-9000 (2016).

53. Snider, B. B. Mechanisms of $\mathrm{Mn}(\mathrm{OAc}) 3$-based oxidative free-radical additions and cyclizations. Tetrahedron 65, 10738-10744 (2009).

\section{Acknowledgements}

We are grateful to NSFC (21901191), Fundamental Research Funds for the Central Universities (2042018kf0023, 2042019kf0006), State Key Laboratory of Bioorganic \& Natural Products Chemistry (BNPC18237) and Wuhan University for financial support. We thank Prof. Tobias Ritter (Max-Planck-Institut für Kohlenforschung, Germany), Prof. Jinbo Hu (Shanghai Institute of Organic Chemistry, China), and Prof. Amir H. Hoveyda (Boston College, USA) for helpful discussion. We are thankful to Prof. Aiwen Lei and Prof. Xumu Zhang at Wuhan University for the generous provision of laboratory and facilities.

\section{Author contributions}

X.S. designed and directed the investigations and composed the manuscript with revisions provided by the other authors. X.C., X.G., and X.S. were involved in the invention of the reagents 1a and 2a. X.C. and X.G. developed the catalytic method. X.C., X.G., Z.L., G.Z., and Z.Z. studied the substrate scope. X.C., X.G., Z.L., G.Z., Z.Z., W.Z., S.L., and X.S. were involved in the analyses of results and discussions of the project.

\section{Competing interests}

The authors declare the following competing interests: X.S., X.C., and X.G. have applied a patent based on the work of this manuscript. All other authors declare no competing interests.

\section{Additional information}

Supplementary information is available for this paper at https://doi.org/10.1038/s41467020-16380-9.

Correspondence and requests for materials should be addressed to X.S.

Peer review information Nature Communications thanks the anonymous reviewer(s) for their contribution to the peer review of this work. Peer reviewer reports are available.

Reprints and permission information is available at http://www.nature.com/reprints

Publisher's note Springer Nature remains neutral with regard to jurisdictional claims in published maps and institutional affiliations.

(c) (i) Open Access This article is licensed under a Creative Commons Attribution 4.0 International License, which permits use, sharing, adaptation, distribution and reproduction in any medium or format, as long as you give appropriate credit to the original author(s) and the source, provide a link to the Creative Commons license, and indicate if changes were made. The images or other third party material in this article are included in the article's Creative Commons license, unless indicated otherwise in a credit line to the material. If material is not included in the article's Creative Commons license and your intended use is not permitted by statutory regulation or exceeds the permitted use, you will need to obtain permission directly from the copyright holder. To view a copy of this license, visit http://creativecommons.org/ licenses/by/4.0/.

(C) The Author(s) 2020 